\title{
So-Called Idiopathic Scoliosis in New Classification. Prophylactics and Therapeutic Aims for Orthopedic Surgery and for General Medicine
}

\section{Prof. Tomasz Karski}

Professor Lecturer in Vincent Pol University in Lublin, Poland. tmkarski@gmail.com; t.karski@neostrada.pl

*Corresponding Author: Prof. Tomasz Karski, Professor Lecturer in Vincent Pol University in Lublin, Poland.

\section{Abstract}

The biomechanical etiology of the so-called idiopathic scoliosis [adolescent idiopathic scoliosis (AIS)] was the subject of research of author from 1984 to 2018. The basic observation comes from the years 1995 - 2007. In presented article is explained the biomechanical etiology of the so-called idiopathic scoliosis, is giving new classification and rules of causal prophylaxis and new treatment. Third group of spine deformity is also the subject for research and therapy for internists, gynecologists, neurologists and other specialists of medicine.

Keywords: Scoliosis. Symptoms. Stiffness of spine. Therapy.

\section{INTRODUCTION}

The article describes the biomechanical etiology of the so-called idiopathic scoliosis (1995 - 2007), known as an adolescent idiopathic scoliosis (AIS). The primary cause of this deformity is "asymmetry of hips movement", limitation of movements in right hip and next "standing 'at ease' on the right leg" and "gait". In 2004 in new classification it was described the group of scoliosis connected only with "gait". The symptoms of this deformity is only stiffness of the spine, without curves or with minimal ones. In 2006 was described the "model of hips movement" which inform about the type of scoliosis in context of adequate rage of movement of right and left hip.

\section{MATERIAL}

In the years 1985 - 2018 in observations and in treatment was - 2500 patients mostly in age $5-18$, small group of cases were in older age, coming with problem of pain. The others 505 persons suspected for scoliosis constituted the control group. The older patients ask for examination not because of deformity, but because of pain, sometimes many years. The were mostly with scoliosis in the second or third group of deformity.

Development of Scoliosis (See Literature 1 - 22)

The scoliosis appears as the secondary deformity connected with asymmetry of hips movements. The asymmetry of child's body and asymmetry of movement of joints was described by Prof. Hans Mau in articles about Syndrome of Contractures. First factors in etiology of scoliosis are connected with asymmetry of movements of hips - limited adduction of right hips in straight position of joints and in some cases limited internal rotation and extension. Next factors in etiology of scoliosis are: "standing 'at ease on the right leg" and "walking". Start of development of every type of scoliosis (see next chapter about classification) is the second year of life. Longer duration of time of standing on the right leg leads after $8-10$ years to fixed scoliosis, left convex curve in lumbar spine or in lumbar - thoracic spine, seldom in sacro- lumbar spine. Three groups and four types of scoliosis are connected with adequate "model of hips movement" (Fig. 1). When the range of movement of left and right hips is symmetrical - never develop scoliosis (Fig. 2, 3). 
So-Called Idiopathic Scoliosis in New Classification. Prophylactics and Therapeutic Aims for Orthopedic Surgery and for General Medicine

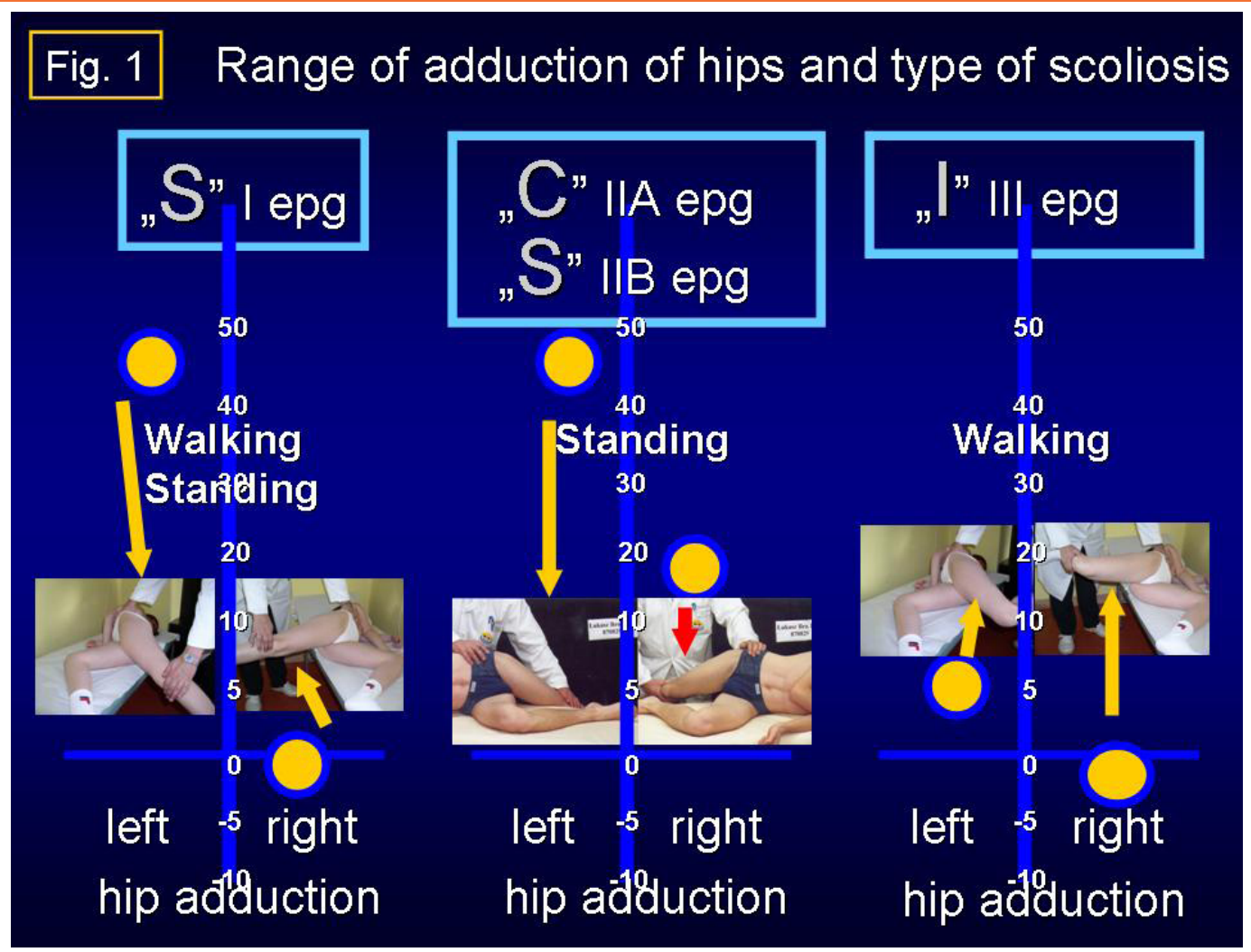

Fig 1. Range of adduction of hips and type of scoliosis.

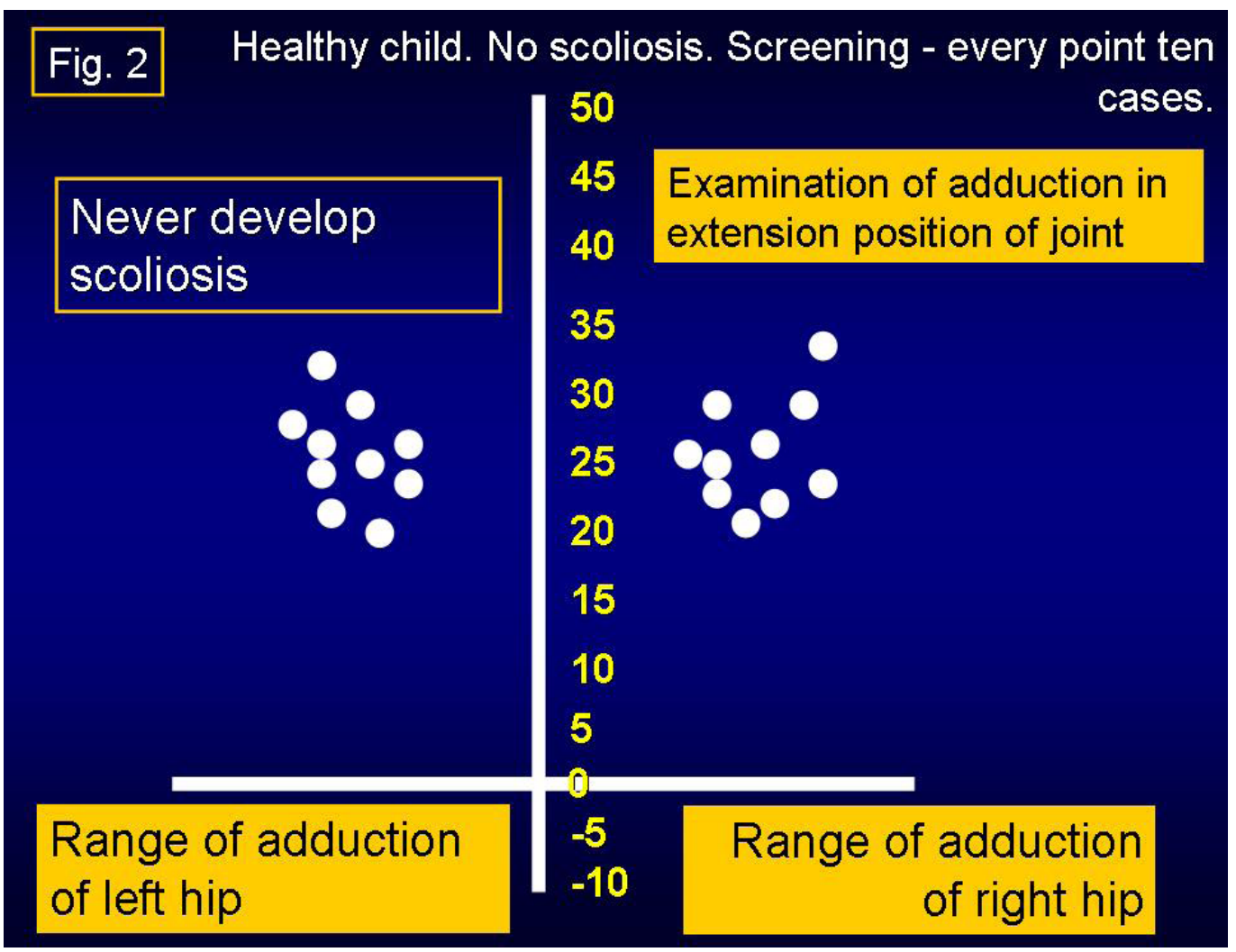

Fig 2. Healthy child. No scoliosis. Screening - every point ten cases. 
So-Called Idiopathic Scoliosis in New Classification. Prophylactics and Therapeutic Aims for Orthopedic Surgery and for General Medicine

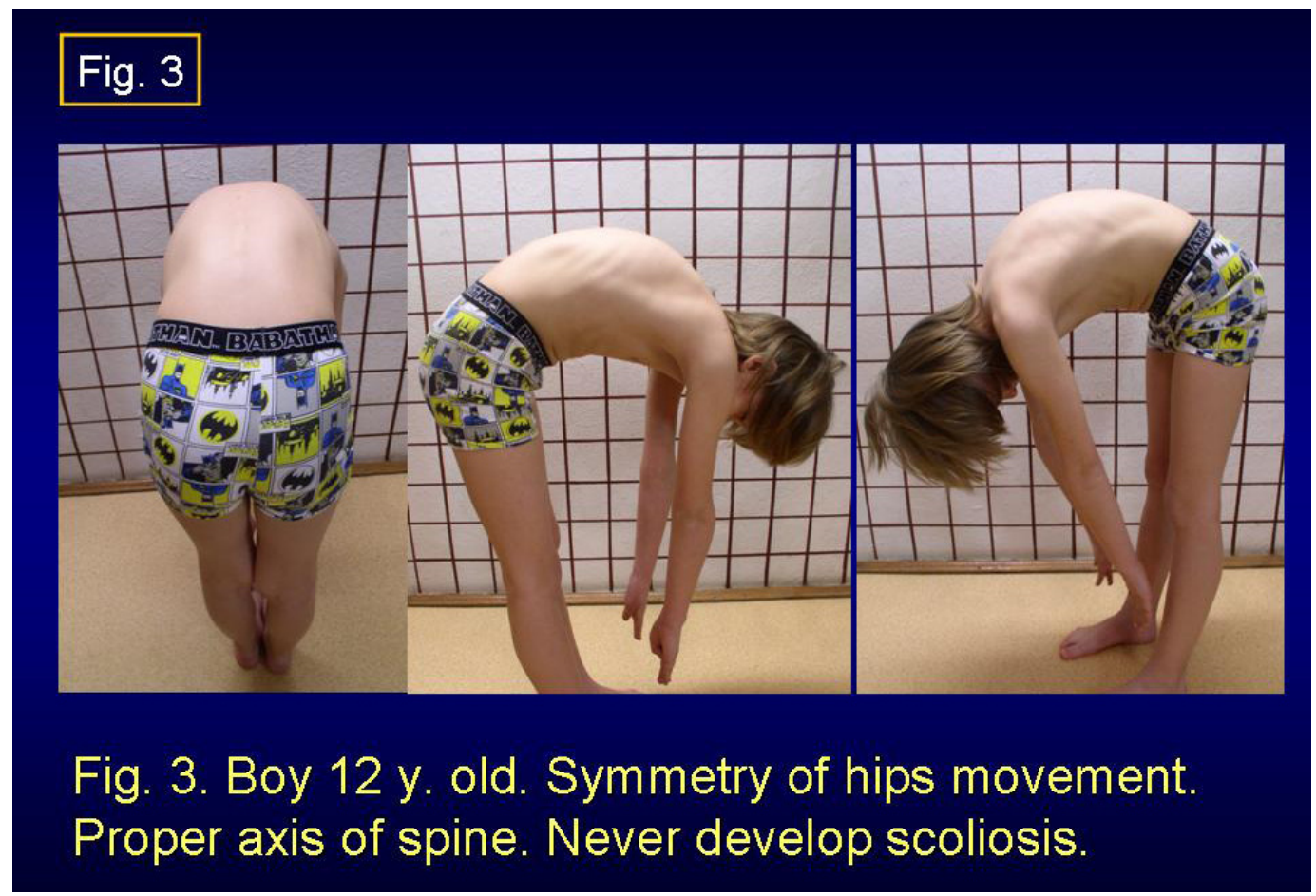

Fig 3. Boy 12 y. old. Symmetry of hips movement. Proper axis of spine. Never develop scoliosis.

In Development of Scoliosis there are Following Stages

$\mathbf{1 /}$ It exist the asymmetry of the movement of hips in all cases of the so-called idiopathic scoliosis. There is limited adduction, internal rotation and extension in the right hip. This phenomenon explain "the left sided Syndrome of Contractures" according to Prof. Hans Mau (Tübingen, Germany).

2/ In gait, in cases with extremely limited movement of adduction, internal rotation of the right hip, is created as "a compensatory movement" in the pelvis and transmitted to the spine as a process leading to the stiffness of the spine. During gait occurs by every step a permanent distortion in the inter-vertebral joints and as result it is rotation deformity leading to rigidity of spine. The phenomenon of "the stiffness" we see in cases of "S" scoliosis in I-st epg and in "I" IIIrd epg group (see - next chapter - classification).

3/ The scoliosis "S" in I etiopathological (epg) group is beside gait also connected with permanent standing 'at ease' on the right leg. The right hip is more stable for standing [!] and in result there are curves.

4/ The permanent standing „at ease' on the right leg, as alone causative influence - starts, widens and fix the curves in "C" II-nd / A epg scoliosis lumbar left convex and in some cases in "S" II-nd / B epg with secondary thoracic right convex curve.

Additional causes of the "S" II-nd / B epg scoliosis is the laxity of joints (typical for the children with Minimal Brain Dysfunction [MBD]) and also result of harmful exercises in previous therapy.

5/ The scoliosis "I" in III-rd epg type is connected only with gait. The character of this scoliosis is only stiffness of the spine. In this deformity there are not curves and not gibbous or there are a very slight. Till $1995-2007$ (research of author) this type of spine deformity was no included to scoliosis group. The stiffness of spine in younger persons make difficulties in some kinds of sport, in older persons can be the cause of annoying, long lasting pain. These older patients need differential diagnosis - because the spine is "only stiff" without curves and doctor must excluded other illnesses before put diagnosis "scoliosis in third group".

\section{Additional Causes in Development of Scoliosis}

In all groups of scoliosis in the development of deformity play an important role the symptoms of Minimal Brain Dysfunctions (MBD) and there are: 
So-Called Idiopathic Scoliosis in New Classification. Prophylactics and Therapeutic Aims for Orthopedic Surgery and for General Medicine

a/ extensor contracture of the trunk, observed even in small children,

b/ anterior tilt of pelvis and in result hiperlordosis of the lumbar spine,

c/ laxity of joints.

\section{Classification}

"The model of hip movements" and type of scoliosis was presented in Fig. 1. When movement of hips, is equal - its mean symmetric of both hips - never develop scoliosis. In such cases there is symmetry of loading of both side of the body during gait and also there is symmetry of time while standing "at ease' on the left : right leg. No act any biomechanical pathological influence on the spine. The growth of spine is proper. When movement of hips are asymmetrical, especially if adduction in strait position of the right hip joint is limited - there is the input to develop scoliosis in three groups and four types.

$\mathbf{1}$ " $\mathbf{S}$ " double scoliosis (I-st epg) with stiff spine (3D). Connection with gait and standing ,at ease' on the right leg (Fig. 4, 5). Scoliosis "S" in I epg type is to see if we observe the disappearing of processes spinosi in thoracic part of spine and beginning of stiffness of

spine even in children in age of $4-6$. Next develop curves. In this type characteristic is progression of the spine deformity.

2a/ "C" - II-nd / A epg scoliosis with flexible spine (1D or 2D). Connection only with standing „at ease' on the right leg.

2b/ "S" - II-nd / B epg scoliosis (2D or 3D). Connection with standing 'at ease' on right leg and additionally with laxity of joints and / or harmful previous exercises (Fig. 6, 7). In these both types of scoliosis the spine is flexible.

Scoliosis "C" II/A epg and "S" II/B epg is to see in age 8 - 10 - 12 years. In these both types no exist or is small progression.

3/ "I" (III-rd epg) scoliosis (2D or 3D) is in form of stiff spine, without curves and without gibbous or with very slight ones. The cause is gait only (Fig. 8, 9, 10). Scoliosis "I" III epg till 1995-2007 - in old classification was never included to "scoliosis deformity", because the symptom were only stiffness and not curves of the spine. This type of scoliosis makes problem in sport of youth and is the cause of back pain in adults what was mentioned above.

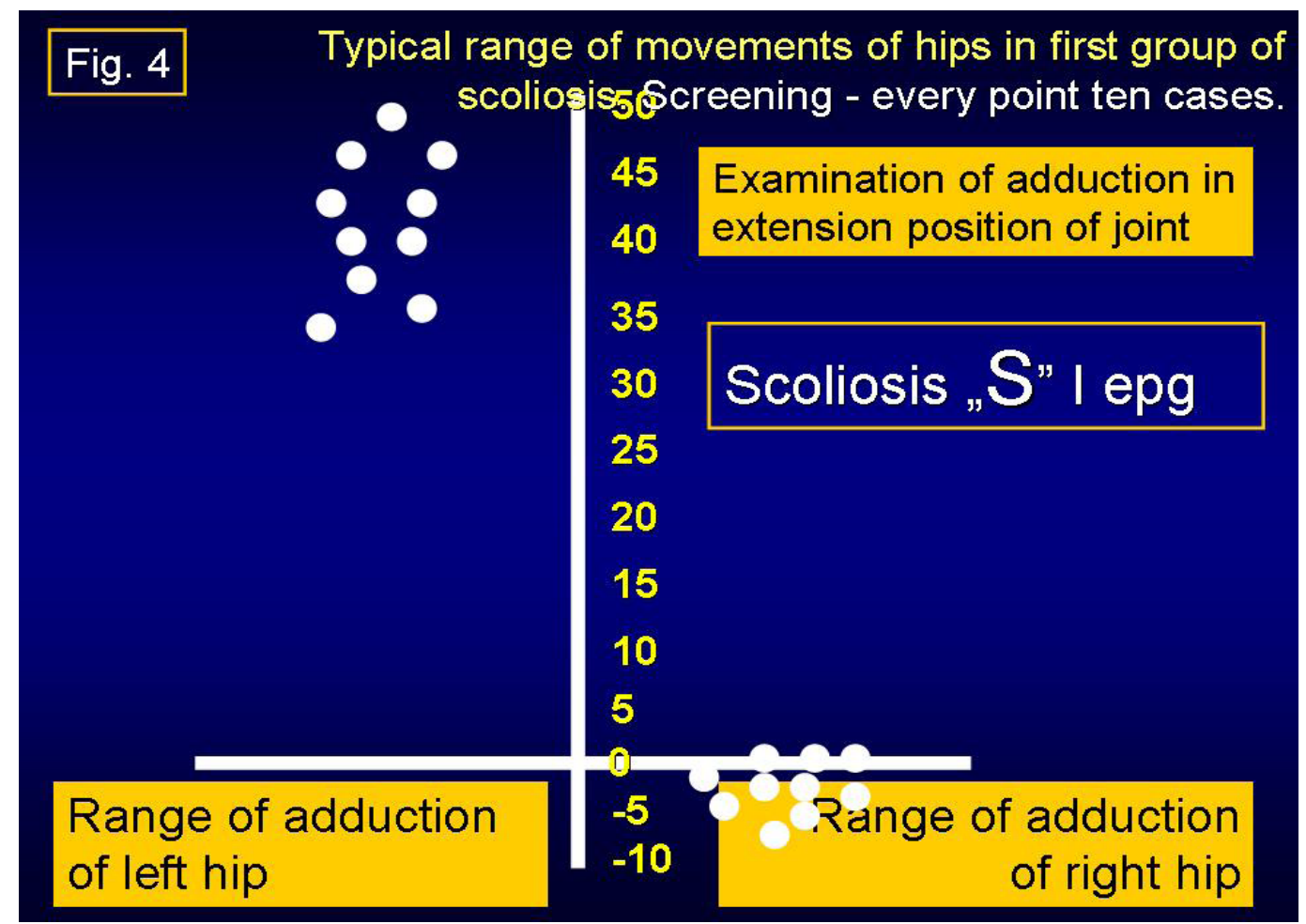

Fig 4. Typical range of movements of hips in first group of scoliosis. Screening - every point ten cases. 
So-Called Idiopathic Scoliosis in New Classification. Prophylactics and Therapeutic Aims for Orthopedic Surgery and for General Medicine



Fig. 5. Girl 16 y. old. Example of "S" scoliosis in I epg. Cause: standing 'at ease' on the right leg and gait. Two curves. Gibbous on the right side of thorax.

Fig 5. Girl 16 y. old. Example of „S” scoliosis in I epg. Cause: standing 'at ease' on the right leg and gait. Two curves. Gibbous on the right side of thorax.



Fig 6. Typical range of movements of hips in second group of scoliosis. Screening - every point ten cases. 
So-Called Idiopathic Scoliosis in New Classification. Prophylactics and Therapeutic Aims for Orthopedic Surgery and for General Medicine

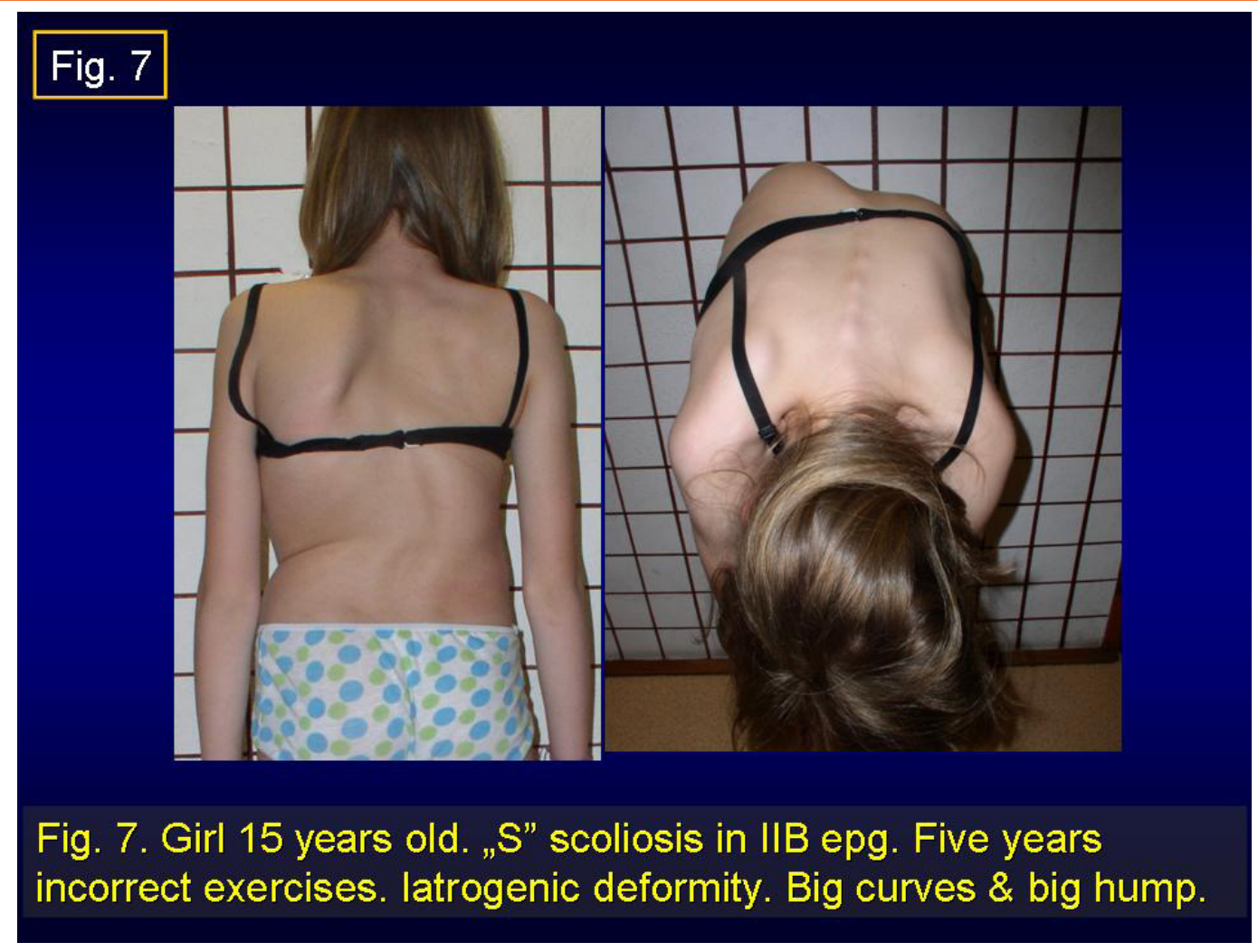

Fig 7. Girl 15 years old. "S” scoliosis in IIB epg. Five years incorrect exercises. Iatrogenic deformity. Big curves \& big hump on the right side.

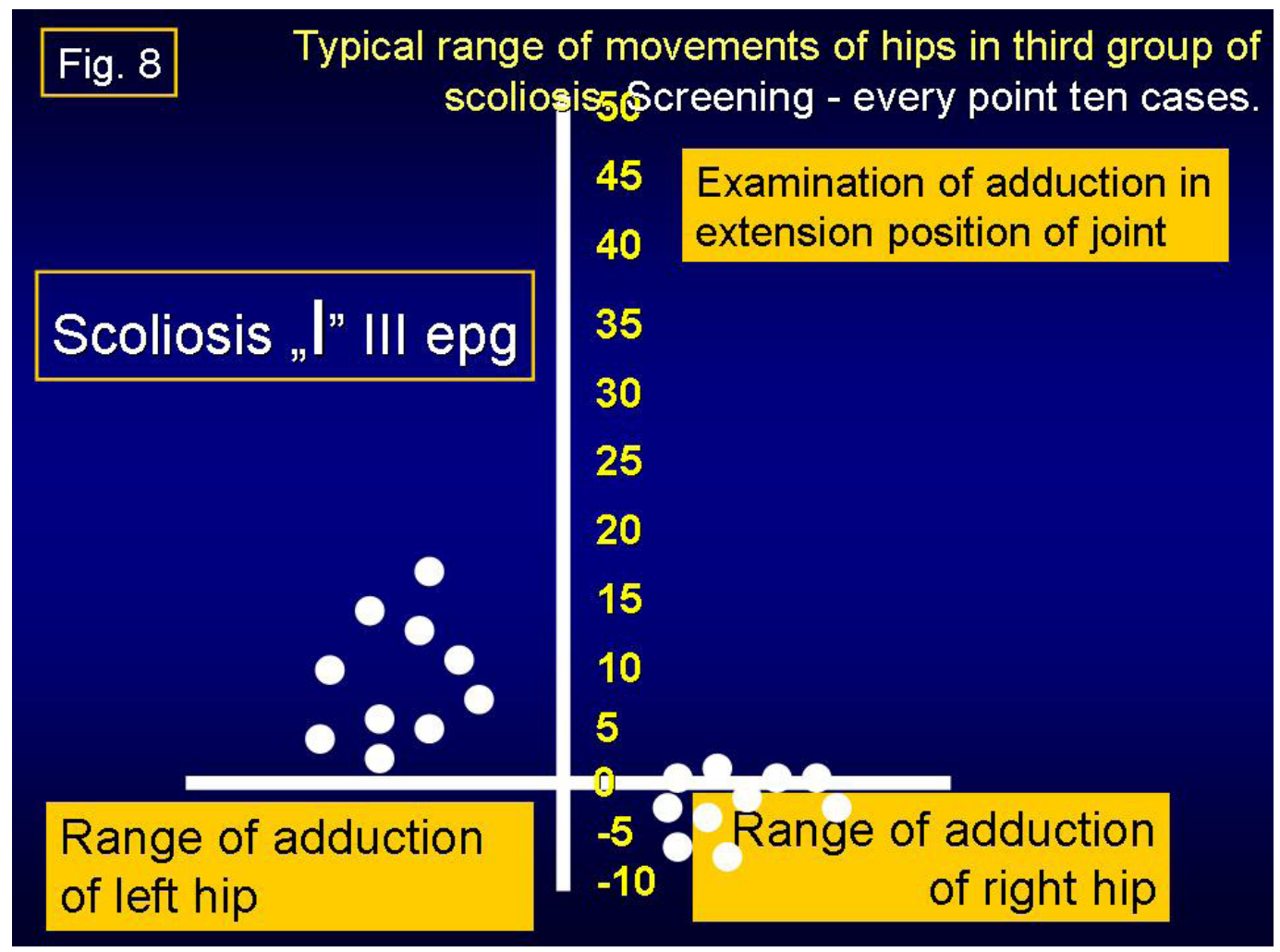

Fig 8. Typical range of movements of hips in third group of scoliosis. Screening - every point ten cases. 
So-Called Idiopathic Scoliosis in New Classification. Prophylactics and Therapeutic Aims for Orthopedic Surgery and for General Medicine

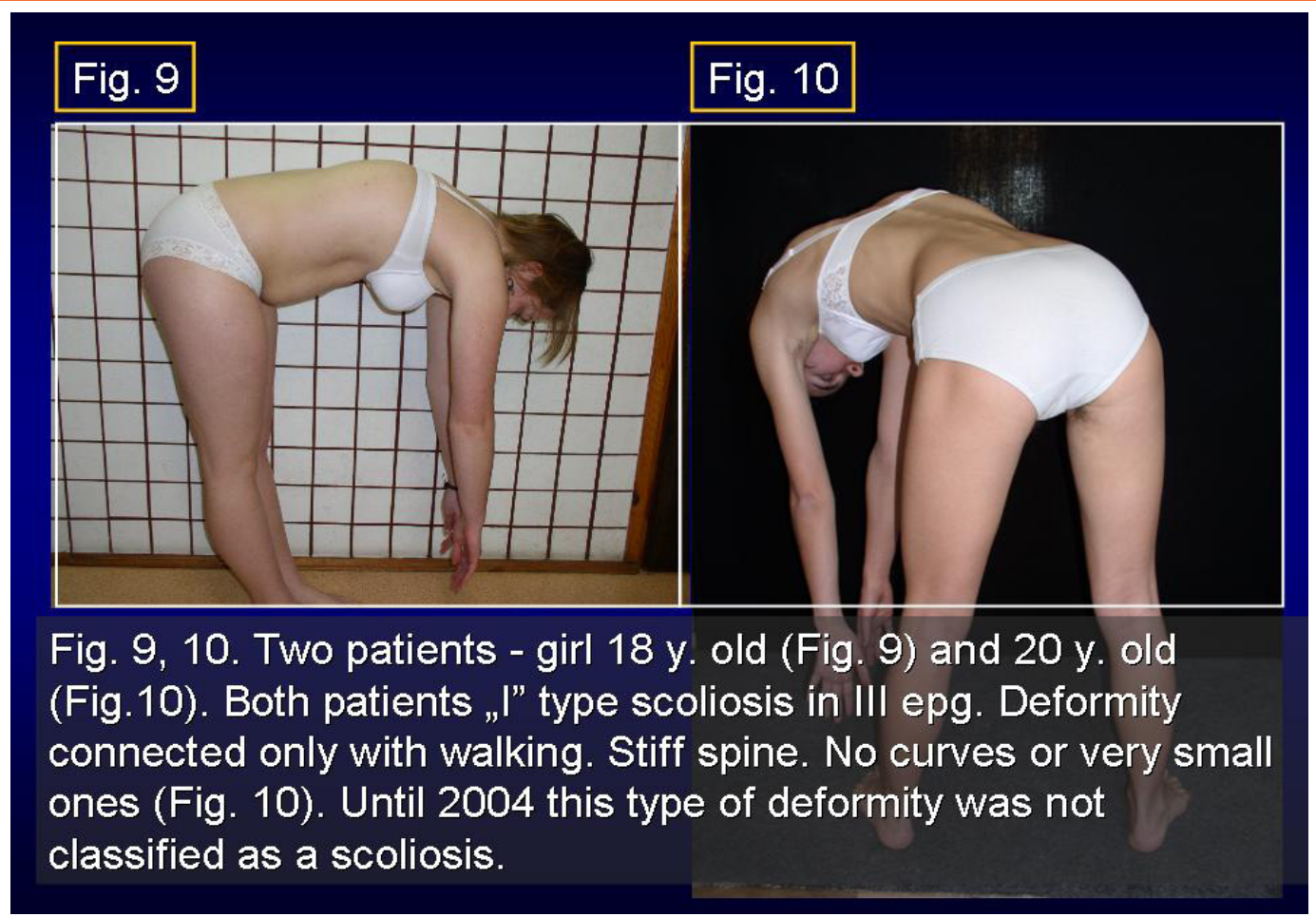

Fig 9, 10. Two patients - girl 18 y. old (Fig. 9) and 20 y. old (Fig.10). Both patients „I" type scoliosis in III epg. Deformity connected only with walking. Stiff spine. No curves or very small ones (Fig. 10). Until 2004 this type of deformity was not classified as a scoliosis.

Discussion and Comments to the New Classification

The "S" scoliosis in I-st etiopathological group can be diagnosed very early, at the age of 3 - 4 . For every doctor and for parents "the fact of standing on the right leg" should be an alarming sign showing the danger of the scoliosis. Similarly - disappearing of processes spinosi and first symptoms of stiffness in Adams test should be the second alarming sign. After harmful extension exercises can develop the "lordotic-scoliosis". Here we must inform that standing 'at ease ' of older persons is the cause of "advanced" degenerative scoliosis.

The "C" scoliosis in II-nd / A epg and "S" scoliosis in II-nd / B epg can be diagnosed at the age of 8 - 10 - 12 . The cause is only a habit of permanent standing „at ease' on the right leg for many years. Initially, it is only the lateral deviation of the spine, but in next years fixed in "C" left convex curve. In the development of the "S" II-nd / B epg scoliosis, occurs additionally, what I mentioned above - the laxity of joints (see symptoms of laxity according Wynne - Davies) and / or harmful exercises. In some cases of "S" II-nd / B epg group we observe in some children "kypho (kifo) -scoliosis". The " $\mathbf{C}$ " and " $\mathbf{S}$ " scoliosis because of permanent standing over years on the right leg can be the cause of degenerative scoliosis in adults people with clinical symptoms of "low back pain".

The "I" scoliosis in III-rd epg - as mentioned above was introduced to new classification in 2004. There is a spine deformity with little or no curvature - but with loss of flexibility of the spine and next with completely stiffness of the spine. The cause of this spine deformity is connected only with the gait. In gait due to a restricted movement of right hip - adduction and internal rotation and with a small these movements in the left hip, make a compensatory rotation movement in the pelvis and spine. This compensatory movement makes, as mentioned above, a permanent distortion in the inter-vertebral joints which result in stiffness and rigidity of the spine. The stiffness of the spine and pain syndromes can be observed even in adolescents, however, nobody considered this to be a special type of scoliosis. These patients, when adult - often suffer because of back pain. In the cases "scoliosis without 
So-Called Idiopathic Scoliosis in New Classification. Prophylactics and Therapeutic Aims for Orthopedic Surgery and for General Medicine

scoliosis" important is differential diagnosis by various specialists - general doctors, internists, neurologists and of course orthopedic surgeons. Here I would like to present the words of Prof. Jan Stokes / USA: "The III-rd etiopathological group is very interesting since it refers also to doctors of other specialties like internist, neurologist, gynecologist and may help in differential diagnosis of 'back pain'".

\section{The Possibility of Causal Prophylaxis and New Treatment of Scoliosis}

The new classification clarifies the need for therapeutic approach to each etiopathological type of scoliosis and provides the possibility to introduce causative prophylaxis. Here is necessary to express, that the " $\mathrm{C}$ " and "S" scoliosis in II-nd / A / B epg group, by adults people, exist because of the permanent standing 'at ease' on the right leg. This spine deformity over years become to be "degenerative scoliosis", the one of the causes of "the back pain". The causal prophylaxis and new treatment is very important. Here I must put your attention, that all extension, others words - strengthening exercises, which were made in past time in many countries for scoliosis patients, were only harmful. After such extension exercises the curves were only bigger, the rib hump more expressed and the stiffness of spine more fix. Now the new knowledge inform - the bad result of therapy were because of incorrect method of treatment (see Literature), but not because of a "specific character of scoliosis". To all patients endangered with scoliosis or just with first symptoms of scoliosis should be introduced the simple and profitable method of therapy - a stretching exercises. The principles of new treatment for all patients are following: $1 /$ no more stand "at ease" on the right leg, 2/ sit relax, 3/ sleep in embryo position, 4/ makes intensive sport, especially stretching and bending exercises for spine.

There is important to receive the symmetry of movements of both hips, symmetry of position of pelvis, to remove the anterior tilt of pelvis and to receive full - flexion, deviation and rotation of the spine, 5/ especially profitable are such sport arts like karate, taekwondo, aikido, kung fu, yoga and other similarly, 6/ especially important is to receive the full movement of right hip as the new, important aim for physiotherapy. For this aim - stretching exercises should be made permanently, every days - as long as will be received full range of movement of hips and spine or to cure the pains syndromes, frequent observed in adults patients. In therapy we should remember do not stand on the right leg - because it can enlarge "degenerative scoliosis".

\section{ConCLUSIONS}

1/In 34 years (1984 - 2018) of authors observations, in all examined cases, it was confirmed the biomechanical etiology of the so-called idiopathic scoliosis.

2/Development of scoliosis and type of spine deformity is connected with pathological "model of hips movements" (T. Karski, 2006) and function standing 'at ease' on the right leg and walking.

$3 /$ There are three groups and four types of scoliosis

"S" scoliosis I-st epg, 3D. Causative influence: standing and gait,

"C" scoliosis II-nd / A epg, 1D. Causative influence: standing,

"S" scoliosis II-nd / B epg, 1D or 2D. Causative influence: standing, plus laxity of joints and/or incorrect exercises in previous therapy,

"I" scoliosis III-rd epg, 2D or 3D. Clinically only stiffness of the spine. Causative influence: gait. The clinical symptom of this deformity can be only "permanent pain".

4/Every type of scoliosis starts to develop in age of 2-3 years.

5/Both - the old tests (Adams \& Meyer test) but also the new tests should be used for early screening.

6/The new tests include:

a/"Lublin side bending test" - more sensible as Adams - Meyer test,

b/Checking of the habit of standing 'at ease' - right versus left leg,

c/Ely Duncan test (or Thom or Staheli test),

d/Adduction of hips test (similarly to Ober test).

$7 /$ In every country should be introduce the causal prophylaxis of scoliosis by using the new therapy - stretching exercises for hips, pelvis, spine plus 
So-Called Idiopathic Scoliosis in New Classification. Prophylactics and Therapeutic Aims for Orthopedic Surgery and for General Medicine

standing only on left leg or on both legs in abduction and internal rotation, rest and sleeping in embryo position. Very important are stretching arts of sport.

8/The "scoliosis deformity" is not only aim of activity of orthopedic surgeons abut also of general doctors, internists, neurologists and others medicine specialists.

\section{Acknowledgement}

I would like to express my many thanks to Honorata Menet for correction of the article.

\section{REFERENCES}

[1] Burwell G, Dangerfield PH, Lowe T, Margulies J. Spine. Etiology of Adolescent Idiopathic Scoliosis: Current Trends and Relevance to New Treatment Approaches, Volume 14/Number 2, Hanley\&Belfus, Inc, May 2000., Philadelphia, p. 324

[2] Green NE, Griffin PP. Hip dysplasia associated with abduction contracture of the contralateral hip. J.B.J.S.1982, 268 63-A, 1273-1281.

[3] Hensinger RN. Congenital dislocation of the hip. Clinical Symp. 1979, 31

[4] Howorth B. The etiology of the congenital dislocation of the hip, Clin. Orthop., 1977, 29, 164-179

[5] Karski T. Etiology of the so-called "idiopathic scoliosis". Biomechanical explanation of spine deformity.Twogroups of developmentofscoliosis. New rehabilitation treatment. Possibility of prophylactics, Studies in Technology and Informatics, Research into Spinal Deformities 4, Vol. 91., IOS Press 2002, Amsterdam, Berlin, 274 Oxford, Tokyo, Washington DC, 37-46.

[6] Karski T, Kalakucki J, Karski J: "Syndrome of contractures" (according to Mau) with the abduction contracture of the right hip as causative factor for development of the so-called idiopathic scoliosis. Stud Health Technol Inform; 2006;34-9

[7] Karski T.: Explanation of biomechanical etiology of the so-called idiopathic scoliosis (1995 - 2007). New 276 clinical and radiological classification" in "Pohybove Ustroji" [Locomotor System] vol. 17, 2010, No.1 + 2, pages: $26-42$ (Czech Republic - 2010)

[8] Karski T.: Biomechanical Etiology of The SoCalled Idiopathic Scoliosis (1995 - 2007) Connection with 279 "Syndrome of Contractures" - Fundamental Information for Paediatricians in Program of Early Prophylactics / Journal of USChina Medical Science, USA, May 2011, Volume 8, No 78

[9] Karski Tomasz: „Factores biomechanicos en la etiologia de las escoliosis dinominadas idiopaticas. Nueva 282 clasificacion. Nuevos test clinicos y nueavo tratamento conservador y profilaxis", Cuestiones de Fisioterapia, MayoAgosto 2010, volumen 39, Numero 2, paginas 85 - 152 [Cuest. Fisioter. 2010, 39 (2); 144 - 152] / Spain [2010]

[10] Karski Tomasz: „Biomechanical Etiology of the So-called Idiopathic Scoliosis (1995-2007). New Classification: 285 Three Groups, Four Sub-types. Connection with „Syndrome of Contractures”, Pan Arab J. Orth. Trauma, vol. (14), No 2, July 2010

[11] Karski Tomasz: Biomechanical Etiology of the Socalled Idiopathic Scoliosis (1995 - 2007). Three Groups and Four Types in the New Classification, Journal of Novel Physiotherapies, OMICS Publishing Group, USA, 2013, S2, 6 pages

[12] Karski Jacek, Tomasz Karski: So-Called Idiopathic Scoliosis. Diagnosis. Tests Examples of Children Incorrect Treated. New Therapy by Stretching Exercises and Results, Journal of Novel Physiotherapies, OMICS Publishing Group, USA, 2013, 3-2, 9 pages

[13] Karski Tomasz, Karski Jacek: „Syndrome of Contractures and Deformities" according to Prof. Hans Mau as Primary Cause of Hip, Neck, Shank and Spine Deformities in Babies, Youth and Adults American Research Journal of Medicine and Surgery, Volume 1, Issue 2, 2015

[14] Karski Tomasz, Karski Jacek: Bóle krzyża problem neurologiczno - ortopedyczny. Objawy. Przyczyny. Leczenie. Back pain - neurology- 
So-Called Idiopathic Scoliosis in New Classification. Prophylactics and Therapeutic Aims for Orthopedic Surgery and for General Medicine

orthopedic problems. Clinic, causes, therapy and prophylaxis. Postępy Neurologii Praktycznej, Wydawnictwo Czelej. 4/2016, P. 9 - 16

[15] Karski Jacek, Karski Tomasz: "Imperfect hips" As a Problem at an Older Age. Early and Late Prophylactic Management before Arthrosis. Jacobs Journal of Physiotherapy and Exercises / USA / Texas. 2016, (2) 1: 015, Pages 7

[16] Mau H. Zur Ätiopathogenese von Skoliose, Hüftdysplasie und Schiefhals im Säuglinsalter. Zeitschrift f. 294 Orthop.1979, 5, 601-5.

[17] Mau H. Die Atiopatogenese der Skoliose, Bücherei des Orthopäden, Band 33, Enke Verlag Stuttgart 1982, 1 - 296
[18] Normelly H.: Asymmetric rib growth as an aetiological factor in idiopathic scoliosis in adolescent girls, Stockholm 1985,1-103

[19] Stokes IAF. Studies in Technology and Informatics, Research into Spinal Deformities 2, Vol. 59., IOS Press 1999, Amsterdam, Berlin, Oxford, Tokyo, Washington DC, 1-385.

[20] Stokes Jan - personal information

[21] Sevastik J, Diab K. Studies in Technology and Informatics, Research into Spinal Deformities 1, Vol. 37., IOS 300 Press 1997, Amsterdam, Berlin, Oxford, Tokyo, Washington, DC 1-509.

[22] www.ortopedia.karski.lublin.pl

Citation: Prof. Tomasz Karski. So-Called Idiopathic Scoliosis in New Classification. Prophylactics and Therapeutic Aims for Orthopedic Surgery and for General Medicine. Open Access Journal of Internal Medicine. 2018; 1(2): 30-39.

Copyright: (C) 2018 Prof. Tomasz Karski. This is an open access article distributed under the Creative Commons Attribution License, which permits unrestricted use, distribution, and reproduction in any medium, provided the original work is properly cited. 